\title{
Liquid Carbon Dioxide Use in the Extraction of Extra Virgin Olive Oil From Olive Paste
}

\author{
Raffaele Romano ${ }^{1}$, Nadia Manzo ${ }^{1}$, Immacolata Montefusco ${ }^{1}$, Annalisa Romano $^{2} \&$ Antonello Santini ${ }^{3}$ \\ ${ }^{1}$ Department of Agriculture, University of Napoli “Federico II" - Via Università, 100 - 80055 Portici (Napoli), \\ Italy \\ ${ }^{2}$ CAISIAL, University of Napoli "Federico II" - Via Università, 100 - 80055 Portici (Napoli), Italy \\ ${ }^{3}$ Department of Pharmacy, University of Napoli “Federico II" - Via D. Montesano 49 - 81100 Napoli, Italy \\ Correspondence: Raffaele Romano, Department of Agriculture, University of Napoli "Federico II"- Via \\ Università, 100 - 80055 Portici (Napoli), Italy. Tel: 39-081-253-9348. E-mail: rafroman@unina.it
}

Received: June 10, 2013 Accepted: December 10, 2013 Online Published: May 10, 2014

doi:10.5539/jfr.v3n4p119 URL: http://dx.doi.org/10.5539/jfr.v3n4p119

\begin{abstract}
In this study the use of liquid carbon dioxide, $\mathrm{CO}_{2}$, for extraction of oil from olive paste (Peranzana cultivar) were examined and extracted oil was compared with oils obtained by centrifugation, pressure and use of chemical solvent.

It is well known that the use of $\mathrm{CO}_{2}$ has many advantages: miscibility with a wide range of molecules, food safety, non-flammability, absence of residues in the extract, possibility of total solvent recovery and no production of olive mill waste water that are highly polluting for the environment and require expansive disposal.

Samples were subjected to the following analyses: determination of Free Fatty Acids (FFA), Peroxides Value (PV), Spectrophotometric Indices, Fatty Acids Composition (FA), determination of biophenols content and determination of Volatile Organic Compounds (VOCs). All samples showed FFA, PV and $\Delta \mathrm{K}$ values within the limits established by law for extra-virgin olive oil. The use of $\mathrm{CO}_{2}$ did not catalyze hydrolysis, oxidation and condensation of double bonds. Centrifuged oils and oils extracted with carbon dioxide presented the lowest PV and FFA values. Extraction with liquid carbon dioxide contributed to an increasing of phenolic content with a value of $270.5 \mathrm{mg} / \mathrm{kg}$, a value twice that of the oils extracted with centrifugation $(135.3 \mathrm{mg} / \mathrm{kg})$ or pressure methods $(173.2 \mathrm{mg} / \mathrm{kg})$. Oil extracted with liquid carbon dioxide showed the greatest amount of t-2-octenal and t-2-heptenal, giving herbaceous and pungent notes. Moreover the presence of aromatic compounds such as limonene, generally absent in olive oils, was only detected in the sample extracted with liquid carbon dioxide.
\end{abstract}

Keywords: liquid carbon dioxide, extra-virgin olive oil, biophenols, Peranzana cultivar

\section{Introduction}

Extra virgin olive oil (EVOO) is the product obtained by processing of the fruit of Olea Europeae. Reg. CE $1531 / 2001$ and further modifications recognizes different types of olive oil, ranging from EVOO to unedible oil, depending on parameters fixed for each category.

Virgin oils preserve the quality of the fruit as they are obtained from fresh olive drupes by using only physical procedures, including centrifugation or pressure extraction methods.

To obtain oils of high quality, in recent years new extraction procedures have been experimented, like the application of compressed fluids, such as $\mathrm{CO}_{2}$. The use of liquid carbon dioxide is taking an important role in food industry, in fact it is already used for many application (Roselius et al., 1974; Zizovic et al., 2007). The wide use of $\mathrm{CO}_{2}$ is due to its advantages: miscibility with a wide range of molecules, food safety, the non-flammability, absence of residues in the extract and the possibility of total solvent recovery. The aim of this study was to examine the effects of $\mathrm{CO}_{2}$ application in the extraction of oil from olive paste and to compare obtained oils with those extracted by use of common solvent (hexane) and by conventional systems (centrifugation and pressure) from the same olive paste. 


\section{Materials and Methods}

\subsection{Sampling}

Olive paste from Peranzana cultivar, collected in November (CROP, 2011), was centrifuged and pressed to obtain the samples OFRC and OFRP, respectively. The same olive paste was extracted by liquid carbon dioxide (sample CDO) using a specific extractor at Centro Sperimentale per la Valorizzazione delle produzioni olearie e vitivinicole, Cercola (Napoli) Italy, and by hexane (sample SOLV).

\section{$2.2 \mathrm{CO}_{2}$ Extraction Procedure From Olive Paste}

The extraction with $\mathrm{CO}_{2}$ was performed as described by Romano et al. (2009). Two different solid-liquid ratios (1:5 and 1:10) were used to evaluate the yield of extraction and three different tests were carried out:

a) Extraction of oil from olive paste and calculation of the yield every 30 min with replacement of solvent (discontinuous process). Solid-liquid ratio 1:5.

b) Extraction of oil from olive paste and calculation of the yield every 30 min with replacement of solvent (discontinuous process). Solid-liquid ratio 1:10.

c) Extraction of oil from olive paste and calculation of the yield after $180 \mathrm{~min}$ without replacement of solvent (continuous process). Solid-liquid ratio 1:10.

\subsection{Determination of Free Fatty Acids (FFA), Peroxides Value (PV) and Spectrophotometric Indices}

The determinations of FFA, PV and Spectrophotometric indices were carried out according to Reg. UE 61/2011. FFA were determined by titratation with $\mathrm{NaOH}$ and expressed as a percent of oleic acid.

$\mathrm{PV}$ were determined by iodometric assay and expressed as meq $\mathrm{O}_{2} / \mathrm{kg}$ oil.

Spectrophotometric indices were measured as absorbance at 232 and $270 \mathrm{~nm}$ and $\Delta \mathrm{K}$ was calculated as: $\mathrm{K} 268-[(\mathrm{K} 262+\mathrm{K} 274) / 2]$.

\subsection{Fatty Acids Composition (FA)}

Analysis of FA composition was performed by gas chromatography (GC) after derivatization to FA methyl esters (FAME) with 2N KOH in methanol, according to the IUPAC standard method (Marquez-Ruiz et al., 2008).

FAME were analyzed on a Perkin Elmer AutoSystem XL gas chromatograph (Perkin Elmer, Waltham, MA, USA) equipped with a PTV (programmed temperature vaporizer), a flame ionization detector, and a capillary column $100 \mathrm{~m} \times 0.25 \mathrm{~mm}$ inner diameter, film thickness of $0.20 \mathrm{~mm}$. Stationary phase $50 \%$ cyanopropyl methyl silicone (Supelco, USA). The carrier gas, helium, was introduced at a flow rate of $20 \mathrm{~cm} / \mathrm{s}$. The oven temperature program was as follows: $120{ }^{\circ} \mathrm{C}$ for $5 \mathrm{~min}, 5{ }^{\circ} \mathrm{C} / \mathrm{min} \operatorname{ramp}$ to $165{ }^{\circ} \mathrm{C}$ for $5 \mathrm{~min}$; and then $10{ }^{\circ} \mathrm{C} / \mathrm{min}$ ramp to $240{ }^{\circ} \mathrm{C}$ for $20 \mathrm{~min}$. The split ratio was $1 / 60$, and the flame ionization detector temperature was set at $260^{\circ} \mathrm{C}$.

The identification of the peaks was made using an external standard (Supelco TM 37 component FAME MIX) by comparing the retention times with those of the pure standard components.

\subsection{Determination of Total Biophenols Content (TB)}

TB were analyzed by a colorimetric method (Folin-Ciocalteau) after hydroalcolic extraction, as indicated by Blekas et al. (2002).

\subsection{Biophenols by HPLC/DAD}

Biophenols were detected by HPLC-DAD, according to the method suggested by International Olive Council (COI/T. 20/ Doc. n. 29, 2009).

\subsection{Determination of Volatile Organic Compounds (VOCs)}

$2 \mathrm{ml}$ of samples were analyzed by dynamic head space (DHS)/GC-MS. 100 microliter of a solution of 10mg/L of undecane, prepared in deodorized oil, were added as internal standard (I.S). The Gas Chromatograph used was an Agilent $6890 \mathrm{~N}$ equipped with an Agilent $5973 \mathrm{~N}$ (Agilent technologies, Palo Alto, CA) mass spectrometer and a capillary column with 5\%-phenyl-methylpolysiloxane $(30 \mathrm{~m} \times 0.25 \mathrm{~mm}$ id $\times 0.25 \mu \mathrm{m}) \mathrm{HP}-5 \mathrm{MS}$ (Agilent technologies, Palo Alto, CA). The carrier gas used was helium at a flow rate of $1.2 \mathrm{~mL} / \mathrm{min}$. The oven temperature program was the following: $45^{\circ} \mathrm{C}$ for $3 \mathrm{~min}, 10{ }^{\circ} \mathrm{C} / \mathrm{min}$ ramp to $90{ }^{\circ} \mathrm{C}$ for $1 \mathrm{~min} ; 20^{\circ} \mathrm{C} / \mathrm{min}$ ramp to $107{ }^{\circ} \mathrm{C}$ for $1 \mathrm{~min}$ and $20^{\circ} \mathrm{C} / \mathrm{min}$ ramp to $240{ }^{\circ} \mathrm{C}$. VOC identification was obtained by comparing the mass spectra with those of the pure standards compounds available in the data system library (NIST 02 and WILEY 275). The quantification of the compounds was made by comparison of peak area with the area of the known amount of I.S. 


\subsection{Statystical Analysis}

All determinations and experiments were performed in triplicate and the results are the average values of three determinations. The data obtained were analyzed by ANOVA using XLSTAT 2006, version 2006.6 (ADDINSOFT, Paris, France), to compare different oils. Differences at $P \leq 0.05$ were considered significant.

\section{Results and Discussion}

\subsection{Yield Extraction}

Discontinuous process using liquid carbon dioxide was carried out for $270 \mathrm{~min}$. As can be seen in Figure 1, after 180 minutes of extraction, no important increase of yield was obtained. An increasing of solvent amount (1:10 ratio) corresponded to an increasing of yield after about $100 \mathrm{~min}$ of extraction.

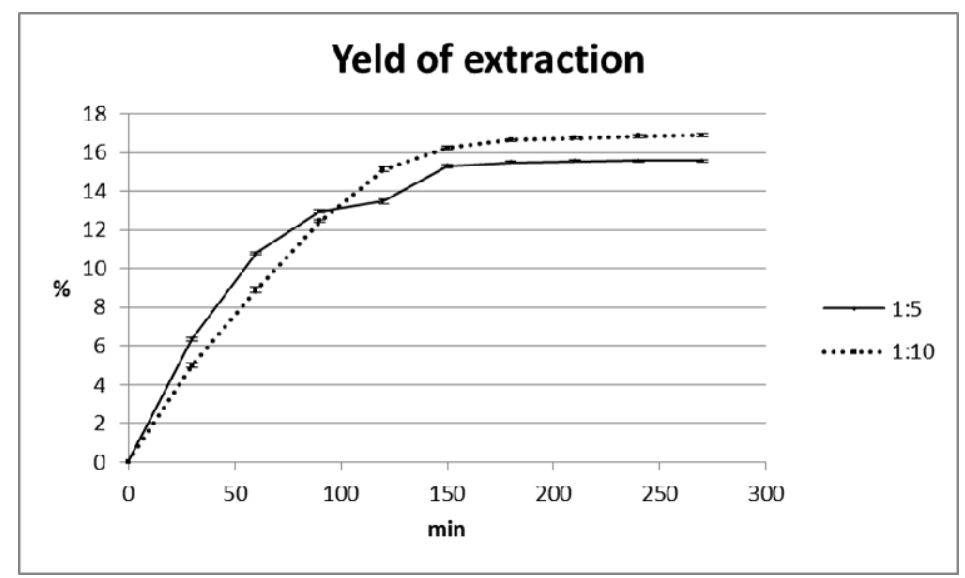

Figure 1. Yield of extraction (\%) obtained using liquid carbon dioxide during discontinuous extraction with 1:5 and 1:10 solid-liquid ratio

Discontinuous procedure showed higher yield values respect to continuous extraction. In fact the yield was $15.49 \%$ and $16.64 \%$, for $1: 5$ and $1: 10$ ratio, respectively, against the $6.9 \%$ and $8.15 \%$ for $1: 5$ and $1: 10$ ratio, respectively, of the continuous extraction after 180 minutes of extraction.

Oils extracted by physical methods showed comparable yields with those obtained with use of liquid carbon dioxide. In fact the first ranged from 17 to $19 \%$ (g oil/ $100 \mathrm{~g}$ olive paste), while oils extracted by liquid $\mathrm{CO}_{2}$ ranged from 16 to $17 \%$ after 270 min of extraction.

\subsection{FFA, PV and Spectrophotometric Indices}

Free fatty acids, peroxide values and Spectrophotometric Indices are reported in Table 1.

Table 1. Free fatty acids (FFA), Peroxides Value (PV) and Spectrofotometric indices of oils extracted by pressure (OFRP), centrifugation (OFRC), hexane (SOLV) and oil extracted by liquid carbon dioxide (CDO)

\begin{tabular}{lcccc}
\hline & OFRP & OFRC & SOLV & CDO \\
\hline FFA (\%) & $0.45^{\mathrm{a}} \pm 0.00$ & $0.25^{\mathrm{c}} \pm 0.01$ & $0.36^{\mathrm{b}} \pm 0.00$ & $0.30^{\mathrm{c}} \pm 0.00$ \\
PV & & & & \\
$\left(\mathrm{meq} \mathrm{O}_{2} / \mathrm{kg}\right)$ & $6.34^{\mathrm{a}} \pm 0.06$ & $4.65^{\mathrm{c}} \pm 0.18$ & $5.36^{\mathrm{b}} \pm 0.04$ & $4.74^{\mathrm{c}} \pm 0.03$ \\
$\Delta \mathrm{K}$ & $-0.005^{\mathrm{b}} \pm 0.000$ & $-0.005^{\mathrm{b}} \pm 0.000$ & $0.005^{\mathrm{b}} \pm 0.000$ & $-0.006^{\mathrm{a}} \pm 0.000$ \\
$\mathrm{~K}_{232}$ & $1.47 \pm 0.02$ & $1.47 \pm 0.01$ & $1.48 \pm 0.01$ & $1.47 \pm 0.00$ \\
$\mathrm{~K}_{270}$ & $0.12 \pm 0.00$ & $0.11 \pm 0.00$ & $0.18 \pm 0.01$ & $0.13 \pm 0.00$ \\
\hline
\end{tabular}

a-c: Different letters for the same parameter correspond to statistically significant differences ( $\leq 0.05)$.

All samples analyzed showed acidity values less than legal limit provided for EVOO $(\leq 0.8 \mathrm{~g}$ oleic acid/ $100 \mathrm{~g}$ oil). Oil extracted by pressure method (OFRP) showed the highest value $(0.45 \%)$. CDO and OFRC showed the 
lowest acidity values, 0.30 and $0.25 \%$, respectively, and no statistically differences $(P<0.05)$ were observed.

In a fresh oil hydroperoxides presence can be an index of oxidation level due to collection, storage and processing of olives (Kiritsakis et al., 1998). PV of all samples was in the legal limit required by law for EVOO $\left(\leq 20 \mathrm{meq} \mathrm{O}_{2} / \mathrm{kg}\right.$ oil).

The sample OFRP showed the highest PV (6.34 meq $\mathrm{O}_{2} / \mathrm{kg}$ oil), while centrifuged oils and oils extracted with carbon dioxide presented the lowest values, 4.65 and 4.74, respectively. In all analyzed samples, spectrophotometric indices, indicating oxidation level, were below the legal limits. Only SOLV had a positive $\triangle \mathrm{K}(0.005)$ but this value was lower than 0.01 .

\subsection{FA Composition}

The most representative fatty acid in olive oil is oleic acid with a percentage of $72 \%$. However, its concentration is very variable, from 60 to $80 \%$, due to different conditions (Aguilera et al., 2005). Palmitic acid (C16:0) is generally present in average values of $14-15 \%$, while the linolenic acid in olive oils is contained in a percentage not exceeding $10 \%$. The analysis of fatty acid composition showed significant differences between the oils extracted by physical methods, compared to oil obtained through the use of liquid $\mathrm{CO}_{2}$ especially in the content of palmitic acid, present in an average concentration of $18 \%$ in CDO, while the samples OFRC and OFRP contained minor amounts ranging from 13.73 to $13.96 \%$.

CDO presented the lowest percentage of long chain fatty acids (LCFA) with a value of $0.73 \%$ respect to all the other samples that ranged from 1.06 to $1.76 \%$. On the other hand, CDO showed the greatest percentage of medium-chain fatty acids (MCFA). This could be due to the different solubility of the fatty acids in the solvent. Also, CDO contained the highest amount of saturated fatty acids (SFA) with a value of $20.46 \%$ respect to the other samples ranged from 16.77 to $17.42 \%$.

\subsection{Biophenols}

The agronomic techniques and processing of olives can modify the concentration of polyphenols in the oil (Montedoro et al., 1989; Servilli et al., 1999; Servilli et al., 2000). Italian oils range between 40 and $900 \mathrm{mg} / \mathrm{kg}$ (Servilli \& Montedoro, 2002) while Greek oils between 20 and $339 \mathrm{mg} / \mathrm{kg}$, expressed as caffeic acid (Blekas et al., 2002).

In olive oil, the presence of phenolic compounds is an index of quality. These molecules give the oil the classic bitter taste (Gutieärrez-Rosales, 2003). As shown in Figure 2, results reported an higher amount of TP in OFRP $(173.2 \mathrm{mg} / \mathrm{kg}$ caffeic acid) than in OFRC $(135.3 \mathrm{mg} / \mathrm{kg}$ caffeic acid). This can be due to the addition of water during centrifugation of olive paste that changes the distribution of phenols, dissolving mainly in the aqueous solution (Servilli et al., 1999). Oils extracted with pressure method generally contains higher amount of phenolic compounds than oils obtained with centrifugation method (Servilli \& Montedoro, 2002). Extraction with liquid carbon dioxide contributed to an increasing of phenolic content, in fact CDO sample showed the highest TP content $(270.5 \mathrm{mg} / \mathrm{kg})$, a value twice that of the oils extracted with centrifugation $(135.3 \mathrm{mg} / \mathrm{kg})$ or pressure methods $(173.2 \mathrm{mg} / \mathrm{kg})$. This can be due to the fact that little amount of liquid carbon dioxide is soluble in water, consequently the carbon dioxide has a higher affinity towards the mentioned molecules. According to Wiebe and Gaddy (1940), $\mathrm{CO}_{2}$ solubility changes as a function of temperature and pressure. Considering the working conditions of the extractor $\left(50\right.$ bar and $\left.25 \pm 2{ }^{\circ} \mathrm{C}\right) \mathrm{CO}_{2}$ solubility in water was about $32-28 \mathrm{ml} / \mathrm{g}$. SOLV sample showed the lowest amount of TP (74.45 $\mathrm{mg}$ caffeic acid $/ \mathrm{kg})$. 


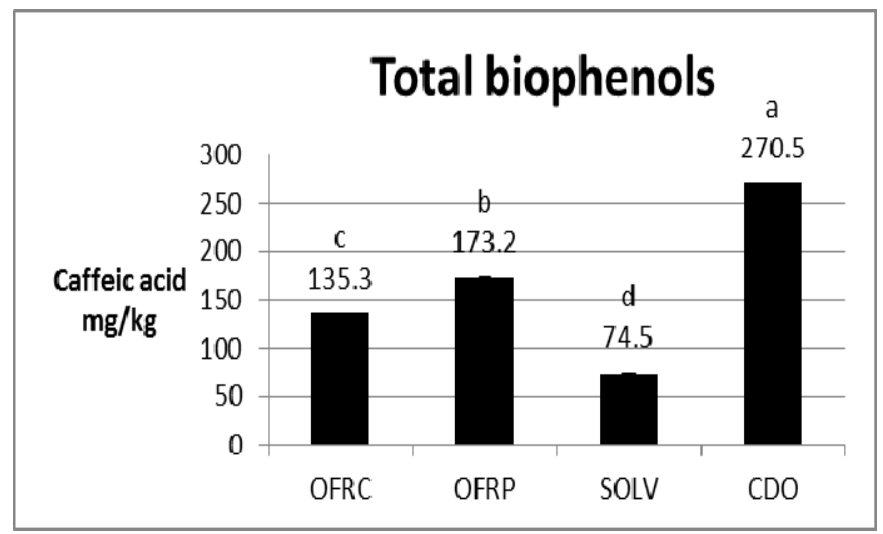

Figure 2. Total biophenols concentration in oil extracted by centrifugation (OFRC), pressure (OFRP), hexane (SOLV) and oil extracted by liquid carbon dioxide (CDO)

a-d: Different letters correspond to statistically significant differences $(\mathrm{P} \leq 0.05)$.

Results obtained with Folin-Ciocolteau method about TP content were confirmed by HPLC-DAD analysis. In Table 2 the concentration ( $\mathrm{mg} / \mathrm{kg}$ of tyrosol) of different phenolic compounds found in all samples was reported. Among extracted oils, CDO showed the highest amount of TP, with a value of about $103 \mathrm{mg} / \mathrm{kg}$, while SOLV showed the lowest amount $(15.81 \mathrm{mg} / \mathrm{kg})$. As shown in the table, in all samples, except for SOLV, the largest amount of phenol compounds belonged to the family of secoiridoids. In oils extracted with classic physical methods the content of secoiridoids ranged from 30.68 in OFRP to $27.69 \mathrm{mg} / \mathrm{kg}$ in OFRC, while oil extracted with carbon dioxide showed a value about twice $(62.71 \mathrm{mg} / \mathrm{kg})$. 
Table 2. Individual biophenol concentration ( $\mathrm{mg} / \mathrm{kg}$ tyrosol) in oils extracted by pressure (OFRP), centrifugation (OFRC), hexane (SOLV) and oil extracted by liquid carbon dioxide (CDO)

\begin{tabular}{|c|c|c|c|c|}
\hline & OFRP & OFRC & SOLV & CDO \\
\hline Phenolic alcohol & $13.54^{\mathrm{a}} \pm 0.29$ & $5.52^{\mathrm{c}} \pm 0.16$ & $11.60^{b} \pm 0.49$ & $1.51^{\mathrm{d}} \pm 0.29$ \\
\hline hydroxytyrosol & $13.21^{\mathrm{a}} \pm 0.29$ & $5.05^{\mathrm{b}} \pm 0.27$ & - & - \\
\hline tyrosol & $0.33^{\mathrm{c}} \pm 0.01$ & $0.47^{\mathrm{c}} \pm 0.11$ & $11.60^{\mathrm{a}} \pm 0.49$ & $1.51^{\mathrm{b}} \pm 0.29$ \\
\hline Phenolic acids & $3.13^{\mathrm{b}} \pm 0.17$ & $1.52^{\mathrm{c}} \pm 0.07$ & $1.03^{\mathrm{c}} \pm 0.05$ & $36.81^{\mathrm{a}} \pm 0.93$ \\
\hline caffeic acid & $2.64^{\mathrm{b}} \pm 0.18$ & $1.14^{\mathrm{c}} \pm 0.08$ & $0.81^{\mathrm{c}} \pm 0.05$ & $35.67^{\mathrm{a}} \pm 0.86$ \\
\hline vanillic acid & $0.49^{\mathrm{a}} \pm 0.01$ & $0.38^{\mathrm{b}} \pm 0.02$ & $0.23^{\mathrm{c}} \pm 0.00$ & - \\
\hline p-coumaric acid & - & - & - & $1.13 \pm 0.07$ \\
\hline Secoiridoides & $30.68^{\mathrm{b}} \pm 0.60$ & $27.69^{\mathrm{c}} \pm 1.72$ & $3.17^{\mathrm{a}} \pm 0.06$ & $62.71^{\mathrm{a}} \pm 0.27$ \\
\hline hydroxyl tyrosyl acetate & $2.66^{\mathrm{a}} \pm 0.04$ & $1.48^{\mathrm{a} . \mathrm{b}} \pm 0.00$ & $0.21^{\mathrm{b}} \pm 0.03$ & - \\
\hline $\begin{array}{l}\text { decarboximethyl oleuropein aglycon, } \\
\text { aldehydic form }\end{array}$ & $0.27^{\mathrm{b}} \pm 0.01$ & - & $0.36^{\mathrm{b}} \pm 0.01$ & $2.10^{\mathrm{a}} \pm 0.16$ \\
\hline oleuropein & $1.09^{\mathrm{b}} \pm 0.06$ & - & $0.37^{\mathrm{c}} \pm 0.01$ & $1.92^{\mathrm{a}} \pm 0.15$ \\
\hline tyrosyl acetate & - & - & $0.44 \pm 0.04$ & - \\
\hline oleuropein aglycone, dialdehydic form & - & $1.02 \pm 0.02$ & - & $0.87 \pm 0.17$ \\
\hline $\begin{array}{l}\text { aglycone decarboxymethyl ligstroside, } \\
\text { dialdehydic oxidized form }\end{array}$ & $4.08^{\mathrm{a}} \pm 0.16$ & $0.43^{\mathrm{d}} \pm 0.09$ & $0.29^{c} \pm 0.01$ & $3.51^{\mathrm{b}} \pm 0.17$ \\
\hline $\begin{array}{l}\text { aglycone decarboxymethyl ligstroside, } \\
\text { dialdehydic form }\end{array}$ & $1.27^{\mathrm{a}} \pm 0.06$ & $0.48^{\mathrm{c}} \pm 0.05$ & - & $0.35^{\mathrm{b}} \pm 0.10$ \\
\hline Ligstroside aglycone, dialdehydic form & - & $0.84 \pm 0.07$ & - & - \\
\hline $\begin{array}{l}\text { oleuropein aglycone, aldehydic and } \\
\text { hidroxilic oxidized form }\end{array}$ & - & - & $0.36^{\mathrm{b}} \pm 0.01$ & $1.67^{\mathrm{a}} \pm 0.05$ \\
\hline $\begin{array}{l}\text { oleuropein aglycone, aldehydic and } \\
\text { hidroxilic form }\end{array}$ & $20.37^{\mathrm{b}} \pm 0.50$ & $22.16^{\mathrm{b}} \pm 1.91$ & $0.45^{\mathrm{c}} \pm 0.03$ & $51.46^{\mathrm{a}} \pm 0.26$ \\
\hline $\begin{array}{l}\text { LIGSTROSIDE aglycone, aldehydic and } \\
\text { hidroxilic form }\end{array}$ & $0.94^{\mathrm{b}} \pm 0.12$ & $1.29^{\mathrm{a} . \mathrm{b}} \pm 0.25$ & $0.68^{\mathrm{b}} \pm 0.03$ & $0.84^{\mathrm{b}} \pm 0.11$ \\
\hline lignans & $0.88 \pm 0.03$ & - & - & - \\
\hline pinoresinol & $0.88 \pm 0.03$ & - & - & - \\
\hline flavones & $1.31^{\mathrm{b}} \pm 0.13$ & $10.99^{\mathrm{a}} \pm 0.19$ & - & $1.34^{\mathrm{b}} \pm 0.54$ \\
\hline apigenin & - & $10.62^{\mathrm{a}} \pm 0.28$ & - & $1.34^{\mathrm{b}} \pm 0.54$ \\
\hline luteolin & $1.31^{\mathrm{a}} \pm 0.12$ & $0.37^{\mathrm{b}} \pm 0.09$ & - & - \\
\hline Total & $49.54^{\mathrm{b}} \pm 0.23$ & $45.71^{\mathrm{b}} \pm 1.08$ & $15.81^{\mathrm{c}} \pm 0.71$ & $102.36^{\mathrm{a}} \pm 5.47$ \\
\hline
\end{tabular}

Among secoiridoids, Oleuropein, as described by Servilli et al. (2009), is one of the most abundant phenolic compounds in the olives while it is contained in little amount or absent in olive oils. In fact it was detected in concentration of $66.61 \mathrm{mg} / \mathrm{kg}$ in the olive paste and in concentration of $1.09,0.37$ and $1.92 \mathrm{mg} / \mathrm{kg}$ in OFRP, SOLV and $\mathrm{CO}_{2}$, respectively.

The aldehydic and hydroxylic form of the aglycone oleuropein was the phenolic compound mainly present in all samples of olive oil, with the exception for SOLV.

ANOVA showed no significant differences in samples OFRC and OFRP, while there were significant differences with oils extracted with carbon dioxide and hexane.

The class of phenolic acids, containing caffeic acid, p-coumaric acid and vanillin, was the most abundant after that of secoiridoids only in $\mathrm{CDO}$ oils.

In all the other samples, the most abundant classes of phenols were phenolic alcohols and flavones.

Little amount of lignans were detected in oils extracted by pressure.

\section{$3.5 \mathrm{VOCs}$}

The complex sensory profile of an oil depends on several variables.

The variety, the degree of ripening, the process of crushing, the kneading temperature, the amount of oxygen in contact with the paste, are all factors that influence the volatile component (Angerosa et al., 1998; Sanchez 
-Ortiz et al., 2008).

The degree of maturation influences the activity and the amount of alcohol dehydrogenase, in fact as the degree of ripening increases, the enzymatic activity decreases (Chervin \& Truett, 1999).

The lack of oxygen in contact with the olive paste and the temperature range significantly affect the activity of lipoxygenase (Kalua et al., 2005).

Several molecules belonging to the classes of aldehydes, ketones, alcohols, esters and other components have been found (Table 3). It is possible to observe that the aldehyde compounds, in particular hexanal in OFRP and $\mathrm{CDO}$ and trans-2-esenal in OFRC, were the most representative compounds in all samples analyzed.

Hexanal, which determines a hint of green apple and trans-2-hexenal reminiscent of the scent of green almond (Morales et al., 1995) are in fact substances that characterize a fresh olive oil.

$\mathrm{CDO}$ appeared to have the greatest amount of $\mathrm{t}$-2-octenal which gives a herbaceous and spicy notes (Aprea et al., 2006), while in the other samples this compound was very low $(1.09 \mu \mathrm{g} / \mathrm{kg}$ in OFRC) or absent (OFRP).

The trans-2-Heptenal, a pungent compound, was present in CDO in high amounts, about $6 \mu \mathrm{g} / \mathrm{kg}$, while the other samples contained from 0.42 to $2.63 \mu \mathrm{g} / \mathrm{kg}$.

Oils extracted by pressure showed the highest amount of alcohols $(58.19 \mu \mathrm{g} / \mathrm{kg})$. In the other samples their concentration was very low ( 0.32 and $3.35 \mu \mathrm{g} / \mathrm{kg}$ in OFRC and CDO, respectively).

Among esters, ethyl acetate and ethyl furan were the only two compounds found in CDO and absent in the other samples. Morales et al., 1995 reported that ethyl acetate is responsible of sweet smell of oils.

Among ketones compounds, 1-penten-3-one, molecule with a hint of sweet and strawberry (Aparicio et al., 1996), was detected only in oil OFRC and heptan-2-one, with smell of fruity, was detected only in CDO.

Among the "other compounds" the presence of limonene, generally absent in olive oils, was only detected in the sample extracted with liquid carbon dioxide, indicating the different solvent power of carbon dioxide respect the existing physical extraction methods. 
Table 3. VOCs concentration $(\mu \mathrm{g} / \mathrm{kg}$ ) of oils extracted by pressure (OFRP), centrifugation (OFRC) and liquid carbon dioxide (CDO)

\begin{tabular}{|c|c|c|c|c|}
\hline & DESCRIPTORS & OFRP & OFRC & CDO \\
\hline 3-methyl butanal & Apple & $0.70 \pm 0.06$ & - & - \\
\hline 2-methyl-2-butenal & & - & - & $0.58 \pm 0.08$ \\
\hline pentanal & Woody, Bitter & - & $0.96^{\mathrm{a}} \pm 0.06$ & $1.04^{\mathrm{a}} \pm 0.01$ \\
\hline hexanal & $\begin{array}{l}\text { Green Apple, } \\
\text { Grassy }\end{array}$ & $53.92^{\mathrm{c}} \pm 1.20$ & $80.95^{\mathfrak{D}} \pm 2.38$ & $168.17^{\mathrm{a}} \pm 7.28$ \\
\hline trans-2-hexenal & Bitter Almonds & $12.35^{\mathrm{c}} \pm 1.10$ & $150.59^{\mathrm{a}} \pm 1.61$ & $42.64^{\mathrm{D}} \pm 0.04$ \\
\hline trans-2-octenal & $\begin{array}{l}\text { Herbaceous, } \\
\text { Spicy }\end{array}$ & - & $1.09^{\mathrm{b}} \pm 0.07$ & $5.88^{\mathrm{a}} \pm 0.06$ \\
\hline octanal & Fatty & $1.81^{\mathrm{a}} \pm 0.07$ & $0.84^{\mathrm{D}} \pm 0.22$ & $2.17^{\mathrm{a}} \pm 0.03$ \\
\hline trans-2-heptenal & Pungent, Soapy & $0.42^{\mathrm{a}} \pm 0.00$ & $2.63^{\mathrm{b}} \pm 0.04$ & $6.08^{\iota} \pm 0.67$ \\
\hline heptanal & Oily & $1.17^{\mathrm{av}} \pm 0.31$ & $0.41^{\mathrm{D}} \pm 0.11$ & $1.42^{\mathrm{a}} \pm 0.53$ \\
\hline Kaldehydes & & $69.95^{\mathfrak{D}} \pm 0.28$ & $237.47^{\mathrm{a}} \pm 4.5$ & $221.9^{\mathrm{a}} \pm 8.63$ \\
\hline 1-propanol & & - & $0.32 \pm 0.01$ & - \\
\hline 3-methyl butanol & Woody, Sweet & $12.72 \pm 2.50$ & - & - \\
\hline 1-hexanol & & $23.55^{\mathrm{a}} \pm 2.28$ & - & $3.35^{\mathrm{b}} \pm 0.31$ \\
\hline 3-hexen-1-ol & Green leaf, Nuts & $7.40 \pm 0.71$ & - & - \\
\hline 2-hexen-1-ol & Cut green grassy & $2.95 \pm 0.20$ & - & - \\
\hline 2-methyl-1-butanol & Winey, Spicy & $11.57 \pm 4.93$ & - & - \\
\hline$\sum$ alcohols & & $58.19^{\mathrm{a}} \pm 3.80$ & $0.32^{\mathrm{D}} \pm 0.01$ & $3.35^{\mathrm{D}} \pm 0.31$ \\
\hline ethyl acetate & Sticky, Sweet & - & - & $8.18 \pm 0.01$ \\
\hline ethyl furan & & - & - & $1.69 \pm 0.12$ \\
\hline hexyl acetate & Sweet, Fruity & $2.31^{\mathrm{a}} \pm 0.47$ & $1.17^{\mathrm{D}} \pm 0.27$ & - \\
\hline 3-hexen-1-ol acetate & $\begin{array}{l}\text { Green leaf, } \\
\text { Nuts }\end{array}$ & $4.51^{\mathrm{a}} \pm 0.33$ & $4.78^{\mathrm{a}} \pm 0.05$ & - \\
\hline$\sum$ esters & & $6.82^{\mathrm{b}} \pm 0.79$ & $5.95^{\mathrm{b}} \pm 0.31$ & $9.87^{\mathrm{a}} \pm 0.13$ \\
\hline 1-penten-3-one & $\begin{array}{l}\text { Sweet, } \\
\text { Strawbarry }\end{array}$ & - & $2.39 \pm 0.24$ & - \\
\hline 6-methyl 2-heptanone & Fruity & $0.95 \pm 0.08$ & - & - \\
\hline heptan-2-one & Sweet, Fruity & - & - & $1.93 \pm 0.13$ \\
\hline 3-methyl-cyclohexen-1-one & & - & $0.37 \pm 0.011$ & - \\
\hline$\sum$ ketones & & $0.95^{\mathfrak{b}} \pm 0.08$ & $2.76^{\mathrm{a}} \pm 0.25$ & $1.93^{\mathrm{a}} \pm 1.60$ \\
\hline limonene & & - & - & $5.38 \pm 0.27$ \\
\hline 3-ethyl heptane & & - & - & $1.75 \pm 0.04$ \\
\hline 3-methyl hexane & & - & - & $1.94 \pm 0.42$ \\
\hline 3-methyl decane & & - & - & $0.46 \pm 0.04$ \\
\hline heptane & & - & $38.39 \pm 3.27$ & - \\
\hline buthyl-1-cycloexene & & $0.36 \pm 0.23$ & - & - \\
\hline 6-methyl-2-undecene & & $0.68 \pm 0.04$ & - & - \\
\hline 3-5 dimethyl-1-hexene & & $0.18 \pm 0.02$ & - & - \\
\hline $\begin{array}{l}\text { 1-1 dimethyl-2-allyl, } \\
\text { ciclopropane }\end{array}$ & & $0.69 \pm 0.17$ & - & - \\
\hline $\begin{array}{l}4-8 \\
1-7 \text {-nonadiene }\end{array}$ & & $1.18^{\mathrm{a}} \pm 0.10$ & $0.42^{\mathrm{c}} \pm 0.01$ & $0.64^{\mathrm{D}} \pm 0.04$ \\
\hline 3-ethyl,1-5-octadiene & & - & $1.17^{\mathrm{a}} \pm 0.29$ & $1.32^{\mathrm{a}} \pm 0.11$ \\
\hline propylciclohexane & & $1.57^{\mathrm{b}} \pm 0.31$ & - & $9.08^{\mathrm{a}} \pm 0.45$ \\
\hline 2,4-dimethyl-1-heptene & & - & - & $9.33^{\mathrm{a}} \pm 0.44$ \\
\hline methyl cyclohexane & & - & $6.87 \pm 0.85$ & - \\
\hline 4-methyl heptane & & $0.88^{\mathrm{b}} \pm 0.55$ & - & $5.35^{\mathrm{a}} \pm 1.17$ \\
\hline$\sum$ other compounds & & $5.54^{\mathrm{c}} \pm 1.43$ & $46.85^{\mathrm{a}} \pm 4.41$ & $32.25^{\mathfrak{b}} \pm 2.10$ \\
\hline
\end{tabular}

a-c: Different letters for the same parameter correspond to statistically significant differences $(\mathrm{P} \leqslant 0.05)$

- Under detection limit $(<0.01 \%)$. 


\section{Conclusions}

Results showed that oils extracted with liquid $\mathrm{CO}_{2}$ presented various advantages: limited hydrolysis and oxidative reactions, higher concentration of biophenols respect to the classic methods, presence of aromatic compounds such as limonene and, very important, no production of olive mill waste water that are highly polluting for the environment and require expansive disposal.

The use of $\mathrm{CO}_{2}$ do not catalyzed hydrolysis, oxidation and condensation of double bonds so that the values of FFA, $\mathrm{PV}$ and $\Delta \mathrm{K}$ were within the limits established by law for EVOO, as the other analyzed samples.

Our results confirmed that this extraction method influenced the pattern of phenolic compounds in EVOO. The addition of water during centrifugation method can eliminate important molecules, such as oleuropein, that are distributed in the vegetable water rather than oil (Servilli \& Montedoro, 2002). In fact, when no water was added during process (pressure method and carbon dioxide extraction), oleuropein was detectable.

$\mathrm{CO}_{2}$ can be considered an alternative to the use of chemical solvents because the extracted oil is qualitatively better in biophenolic content and also safer considering the possibility that traces of the most common solvent used may remain in the finished product, while $\mathrm{CO}_{2}$ can be totally removed and recovered.

\section{References}

Aguilera, M. P., Beltrán, G., Ortega, D., Fernández, A., Jiménez, A., \& Uceda, M. (2005). Characterisation of virgin olive oil of Italian olive cultivars: 'Frantoio' and 'Leccino', grown in Andalusia. Food Chemistry, 89, 387-391. http://dx.doi.org/10.1016/j.foodchem.2004.02.046

Angerosa, F., d'Alessandro, N., Basti, C., \& Vito, R. (1998). Biogeneration of volatile compounds in virgin olive oil: their evolution in relation to malaxation time. J. Agric. Food Chem., 46, 2940-2944. http://dx.doi.org/10.1021/jf970641m

Aparicio, R., Morales, M. T., \& Alonso, M. V. (1996). Relationship Between Volatile Compounds and Sensory Attributes of Olive Oils by the Sensory Wheel. J. Am. Oil Chem. Soc., 73, 1253-1264. http://dx.doi.org/10.1007/BF02525454

Aprea, E., Biasioli, F., Sani, G., Cantini, C., Tilmann, D. M., \& Gasper, F. (2006). Proton Transfer Reaction-Mass Spectrometry (PTR-MS) Headspace Analysis for Rapid Detection of Oxidative Alteration of Olive Oil. J. Agric. Food Chem., 54, 7635-7640. http://dx.doi.org/10.1021/jf060970r

Blekas, G., Vassillakis, C., Harizanis, C., Tsimidou, M., \& Boskou, D. G. (2002). Biophenols in table olives. J. Agric. Food Chem., 50, 3688-3692. http://dx.doi.org/10.1021/jf0115138

Chervin, C., \& Truett, J. K. (1999). Alcohol Dehydrogenase Expression and Alcohol Production during Pear Ripening. J. Amer. Soc. Hort. Sci., 124, 71-75.

COI/T. 20/ Doc. n. 29 Novembre 2009: Determinazione dei biofenoli degli oli di oliva mediante HPLC.

Gutieärrez-Rosales, F., Riäos, J. J., \& Goä Mez-Rey, Ma. L. (2003). Main polyphenols in the bitter taste of virgin olive oil. Structural confirmation by on-line high-performance liquid chromatography electrospray ionization mass spectrometry. J. Agric. Food Chem., 51, 6021-6025. http://dx.doi.org/10.1021/jf021199x

Kalua, C. M., Allen, M. S., Bedgood, D. R., Andrea, J., Bishop, G., \& Prenzler, P. D. (2005). Discrimination of Olive Oils and Fruits into Cultivars and Maturity Stages Based on Phenolic and Volatile Compounds. $J$. Agric. Food Chem., 53, 8054-8062. http://dx.doi.org/10.1021/jf051233i

Kiritsakis, A., Nanos, G. D, Polymenopoulos, Z., Thomai, T., \& Sfakiotakis, E. M. (1998). Effect of Fruit Storage Conditions on Olive Oil Quality. JAOCS, 75, 721-724. http://dx.doi.org/10.1007/s11746-998-0212-7

Márquez-Ruiz, G., Martín-Polvillo, M., Velasco, J., \& Dobarganes, C. (2008). Formation of oxidation compounds in sunflower and olive oils under oxidative stability index conditions. Eur. J. Lipid Sci. Technol., 110, 465-471. http://dx.doi.org/10.1002/ejlt.200700246

Montedoro, G. F., Garofolo, L., Bertuccioli, M., \& Pannelli, G. (1989). Influence of the cultivars and pedoclimatic conditions on the virgin olive oil quality. Proceedings of 6th International Flavor Conference, Rethymnon, Crete, Greece. Ed. G. Charalambous, Elsevier Science Publishers B.V., Amsterdam (The Netherlands), pp. 881-891.

Morales, M. T., Alonso, N. V., Rios, J. J., \& Aparicio, R. (1995). Virgin olive oil aroma: relationship between volatile compounds and sensory attributes by chemometrics. J. Agric. Food Chem., 43, 2925-2931. http://dx.doi.org/10.1021/jf00059a029 
Reg. CE 1531/2001 del Consiglio del 23 luglio 2001 che fissa le descrizioni e definizioni degli oli d'oliva e degli oli di sansa di oliva, in vigore dal $1^{\circ}$ novembre 2003.

Reg. UE 61/2011 della Commissione che modifica il regolamento (CEE) n. 2568/91 relativo alle caratteristiche degli oli d'oliva e degli oli di sansa d'oliva nonché ai metodi di analisi ad essi attinenti.

Romano, R., Nota, G., Giordano, A., Magaldi, G., \& Spagna Musso, S. (2009). Extraction of lipids and essential oils from vegetable matrix by liquid carbon dioxide. Chemical engineering transactions, 17, Ed Sauro Perucci.

Roselius, Vitzthum, Hubert. (1974). Method for the Production of Caffeine-Free Coffee Extract U.S. Patent 3, 843,824 .

Sanchez-Ortiz, A., Romero, C., Perez, A. G., \& Sanz, C. (2008). Oxygen Concentration Affects Volatile Compound Biosynthesis during Virgin Olive Oil Production. J. Agric. Food Chem., 56, 4681-4685. http://dx.doi.org/10.1021/jf8004838

Servilli, M., \& Montedoro, G. F. (2002). Contribution of phenolic compounds to virgin olive oil quality. Eur. L. $\begin{array}{llll}\text { Lipid } & \text { Sci. Technol., } & \text { 602-613. }\end{array}$ http://dx.doi.org/10.1002/1438-9312(200210)104:9/10<602::AID-EJLT602>3.0.CO;2-X

Servilli, M., Esposto, S., Fabiani, R., Urbani, S., Taticchi, A., Mariucci, F., ... Montedoro, G. F. (2009). Phenolic compounds in olive oil: antioxidant, health and organoleptic activities according to their chemical structure. Inflammophamacology, 17, 76-84. http://dx.doi.org/10.1007/s10787-008-8014-y

Servilli, M., Baldioli, M., Begliomini, A. L., Selvaggini, R., \& Montedoro, G. F. (2000). The phenolic and volatile compounds of virgin olive oil: relationships with the endogenous oxidoreductases during the mechanical oil extraction process. In V. Lanzotti \& O. Taglialatela-Scafati (Eds.), Flavour and Fragrance Chemistry (pp. 163-173) Kluwer Academic Publishers, Dordrecht (The Netherlands),

Servilli, M., Baldioli, M., Mariotti, F., \& Montedoro, G. F. (1999). Phenolic composition of olive fruit and virgin olive oil: distribution in the constitutive parts of fruit and evolution during oil mechanical extraction process. Acta Horticulturae, 474, 609-619.

Wiebe, R., \& Gaddy, V. L. (1940). The Solubility of Carbon Dioxide in Water at Various Temperatures from 12 to $40^{\circ}$ and at Pressures to 500 Atmospheres. Critical Phenomena. Journal of the American Chemical Society, 62, 815-817. http://dx.doi.org/10.1021/ja01861a033

Zizovic, I., Stamenić, M., Orlović, A., \& Skala, D. (2007). Supercritical carbon dioxide extraction of essential oils from plants with secretory ducts: Mathematical modelling on the micro-scale. The journal of supercritical fluids, 39, 338-346. http://dx.doi.org/10.1016/j.supflu.2006.03.009

\section{Copyrights}

Copyright for this article is retained by the author(s), with first publication rights granted to the journal.

This is an open-access article distributed under the terms and conditions of the Creative Commons Attribution license (http://creativecommons.org/licenses/by/3.0/). 